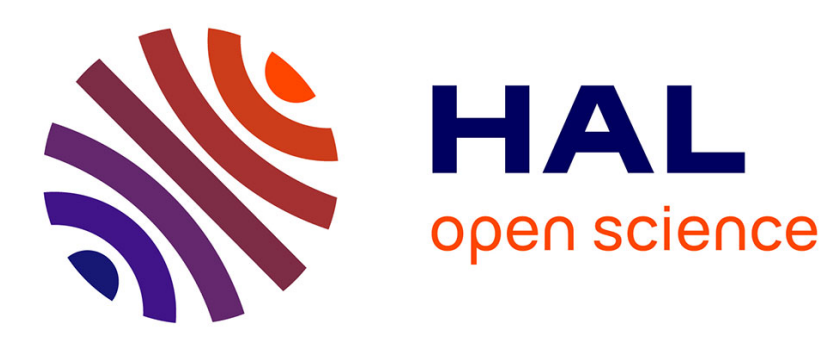

\title{
Impact Fracture Testing of Engineering Polymers (Part 2)
}

\author{
Z. Major, R. Lang
}

\section{To cite this version:}

Z. Major, R. Lang. Impact Fracture Testing of Engineering Polymers (Part 2). Journal de Physique IV Proceedings, 1997, 07 (C3), pp.C3-1005-C3-1009. 10.1051/jp4:19973169 • jpa-00255459

\section{HAL Id: jpa-00255459 https://hal.science/jpa-00255459}

Submitted on 1 Jan 1997

HAL is a multi-disciplinary open access archive for the deposit and dissemination of scientific research documents, whether they are published or not. The documents may come from teaching and research institutions in France or abroad, or from public or private research centers.
L'archive ouverte pluridisciplinaire HAL, est destinée au dépôt et à la diffusion de documents scientifiques de niveau recherche, publiés ou non, émanant des établissements d'enseignement et de recherche français ou étrangers, des laboratoires publics ou privés. 
J. PHYS IV FRANCE 7 (1997)

Colloque C3, Supplément au Journal de Physique III d'août 1997

\title{
Impact Fracture Testing of Engineering Polymers (Part 2)
}

\author{
Z. Major and R.W. Lang*, \\ Joanneum Research Forschungsges.m.b.H, Institute for Polymer Technology, Franz Josef Str. 18, \\ 8700 Leoben, Austria \\ * University of Leoben, Institute of Materials Science and Testing of Plastics, Franz Josef Str. 18, \\ 8700 Leoben, Austria
}

\begin{abstract}
To characterize the dynamic fracture behaviour of high density poly(ethylene) (PE- $\mathrm{HD})$ and poly(oxymethylene) (POM), instrumented impact tests were performed with a servohydraulic test system using various specimens under bending and tensile loading. The objectives of this study were to develop and implement a test methodology and a data recording and reduction scheme for various test speeds and impact rates $(0.001$ to $8 \mathrm{~m} / \mathrm{s})$, and to determine the effect of the impact rate on the fracture toughness of PE-HD and POM. The data reduction to determine dynamic fracture toughness values was carried out according to different procedures taking account of the specific impact rates and the deformation behaviour of the materials tested.

Résumé. Pour caractériser le comportement de rupture aux grandes vitesses de polyéthylène de haute densité (PE$\mathrm{HD}$ ) et polyoxyméthylène (POM), on a fait des essais d'impact instrumentés avec une machine d'essai servohydraulique avec des spécimens divers sous flexion et traction. Les objectifs de ces études etaient le dévelopment et l'implémentation d'une méthodologie d'essai et un schéma d'acquisition et réduction des données pour des vitesses d'essai différents (de 0.001 a $8 \mathrm{~m} / \mathrm{s}$ ), et la détermination de l'effet de la vitesse d'impact sur le facteur critique d'intensité des contraintes, $\mathrm{K}_{\mathrm{Ic}}$ de PE-HD et POM. La réduction des données pour évaluer $\mathrm{K}_{\mathrm{Ic}}$ a été réalisée en prenant les vitesses d'impact spécifiques et le comportement de déformation des matériaux testés en consideration.
\end{abstract}

\section{INTRODUCTION}

For many engineering applications, impact fracture behavior is of prime practical importance. While impact properties of plastics are usually characterized in terms of notched or unnotched impact fracture energies, there has been an increasing tendency to also apply fracture mechanics techniques over the last decade $[1,2]$. However, due to dynamic effects several special problems are encountered in high rate fracture testing $[1,3,4]$. For example, when a specimen is loaded by impact, the transducers will yield a signal which is a complex combination of the following factors:

- true mechanical response of the specimen,

- inertial loading of the striker as a result of specimen acceleration,

- low-frequency oscillations caused by stored elastic energy and reflected stress waves,

- high-frequency noise caused primarily by the conditional amplification system.

The first of the above components is obviously the goal of the signal analysis, but the second and third factors can overshadow the true mechanical response especially at higher impact rates. While the control of dynamic effects at impact rates up to $1 \mathrm{~m} / \mathrm{s}$ frequently makes use of mechanical damping in the load transmission by placing a soft pad between the striker and the specimen, for intermediate impact rates above $1 \mathrm{~m} / \mathrm{s}$ to $10 \mathrm{~m} / \mathrm{s}$, a dynamic technique referred to as dynamic key curve method (DKC), recently proposed by Böhme [3], may be applied. Furthermore, for this impact rate range, a modified tensile type specimen geometry together with damping elements has been suggested by other investigators to determine fracture toughness values with the conventional force based method [4].

The objective of this study was to develop, implement and compare different test methodologies and data recording and reduction schemes to determine impact rate dependent fracture toughness values for two semicrystalline polymers. Included in the investigations were bending and tensile specimens which were exposed to impact rates from 0.001 to $8 \mathrm{~m} / \mathrm{s}$ using a servohydraulic test system instrumented for high rate testing. 


\section{EXPERIMENTAL}

\subsection{Materials and Specimens}

Two polymeric materials, commercial grade poly(oxymethylene) (POM) (Hostaform C 2552, Hoechst AG, Frankfurt/Main, D) and commercial grade poly(ethylene) (PE-HD) (Daplen 3964, PCD Polymere, Linz, A), were used in this study. The POM was supplied as extruded sheets with a nominal thickness of 10 to $12 \mathrm{~mm}$. The PE-HD was compression moulded to plaques with a nominal thickness of $10 \mathrm{~mm}$. Single edge notched bending (SENB) and compact type (CT) specimens according to a configuration defined in [1], and single edge notched tensile (SENT) specimens according to a configuration defined in [5] were machined from the sheets and plaques, respectively, and subsequently notched and razor blade precracked. The normalized crack length, a/W ( $\mathrm{a}$ being the crack length and $\mathrm{W}$ the specimen width), ranged from 0.45 to 0.55 .

\subsection{Testing and Data Acquisition}

A fully digitized servohydraulic test machine (MTS 831.59 Polymer Test System, MTS Corp., Minneapolis, USA) was used to perform all of the tests. The striker for the SENB specimens and the fixture for the CT and SENT specimens was equipped with a piezo load cell (Kistler 9041A). The loadpoint displacement associated with the striker movement was determined from an LVDT signal of the piston. For impact rates above $1 \mathrm{~m} / \mathrm{s}$ some specimens were also instrumented. In several test series, strain gages (CEA-06-032UW-120, CEA -06-062UW-350, Measurements Group Inc. Raleigh, USA) were applied to the specimen near the crack tip. In some other instances, crack propagation detector strips (TK09-CPA01-005/DP) were placed just ahead of the crack tip (same supplier as before).

\subsection{Data Reduction}

Typical examples of force/load-point displacement curves of SENB specimens for impact rates of $0.1 \mathrm{~m} / \mathrm{s}$, $1 \mathrm{~m} / \mathrm{s}$ and $3.3 \mathrm{~m} / \mathrm{s}$ are shown in Fig. 1 for POM and PE-HD. While the recorded non-damped signal at 0.1 $\mathrm{m} / \mathrm{s}$ is of sufficient quality to directly determine the fracture force, $F_{Q}$, significant force oscillations are visible in the non-damped signal at $1 \mathrm{~m} / \mathrm{s}$. An equivalent diagram for a loading rate of $1 \mathrm{~m} / \mathrm{s}$ with a plasticene damping material placed at the striker tip is also shown in Fig. la and compared to the nondamped case. Force oscillations are seen to be significantly reduced, thus allowing again for a direct determination of $F_{Q}$. For a loading rate of $3.3 \mathrm{~m} / \mathrm{s}$ the inertial forces apparently overshadow the true mechanical response of the specimen (see also in Fig. 1). Hence, a force based analysis is not possible in this case.

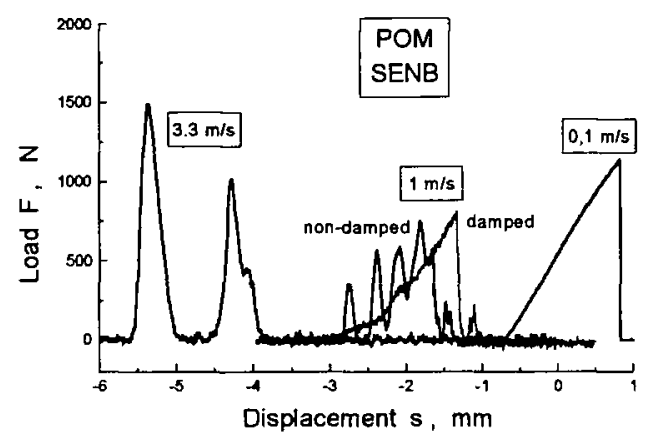

(a)

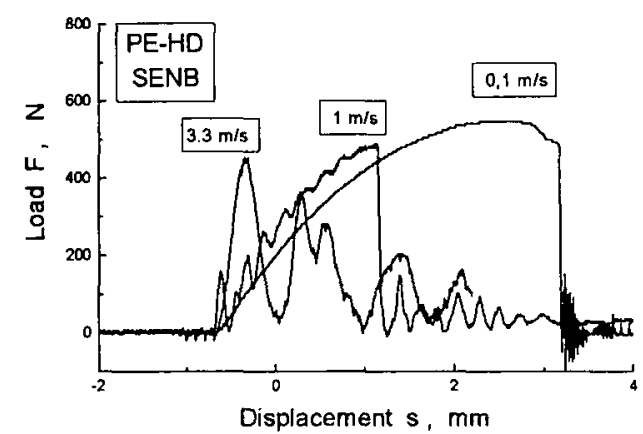

(b)

Fig. 1: Force/load-point displacement records for SENB specimens of POM and PE-HD at impact rates of $0.1 \mathrm{~m} / \mathrm{s}, 1 \mathrm{~m} / \mathrm{s}$. and $3.3 \mathrm{~m} / \mathrm{s}$ 
For POM loaded at impact rates up to $1 \mathrm{~m} / \mathrm{s}$ in case of SENB specimens and up to $8 \mathrm{~m} / \mathrm{s}$ in case of CT specimens, fracture toughness values, $\mathrm{K}_{\mathrm{lc}}$, were calculated as follows:

$$
K_{I c}=\frac{F_{Q}}{B W^{1 / 2}} f(a / W)
$$

where $F_{Q}$ is the fracture force, $B$ is the specimen thickness, $W$ is the specimen width, and a is the crack length.

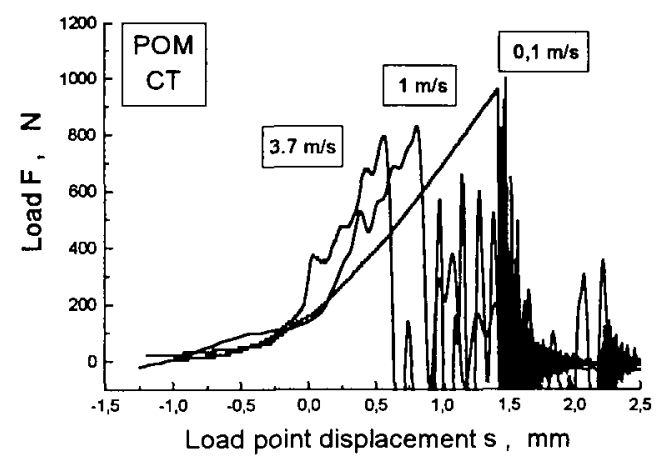

(a)

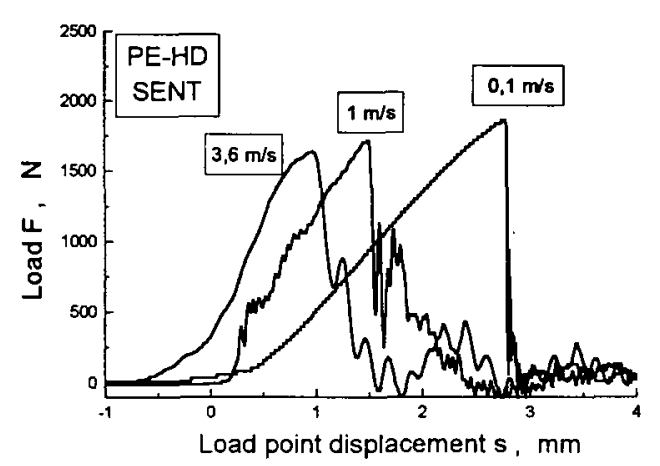

(b)

Fig. 2: Force/load-point displacement records for $C T$ and SENT specimens of POM and PE-HD at impact rates $0.1 \mathrm{~m} / \mathrm{s}$, $1 \mathrm{~m} / \mathrm{s}$ and 3.6 to $3.7 \mathrm{~m} / \mathrm{s}$.

In sharp contrast to POM, PE-HD reveals distinct non-linear load-displacement characteristics with an $\mathrm{F}_{\max } / \mathrm{F}_{\mathrm{Q}}$ ratio larger than 1.1 (see Fig. $1 \mathrm{~b}$ ). However, once $\mathrm{F}_{\max }$ is reached, unstable crack propagation in a quasi-brittle fracture mode occurs. As expected, the degree of non-linearity decreases with increasing test speed; simultaneously the maximum force is also slightly reduced. As the methodology of linear elestic fracture mechanics (LEFM) to determine $K_{\mathrm{Ic}}$ is not applicable for the high degree of non-linearity observed, a data reduction scheme based on critical value of the J-integral up to $F_{\max }$ was applied. Accordingly, critical values for $\mathrm{J}_{\mathrm{c}}$ and $\mathrm{K}_{\mathrm{Jc}}$ were determined as follows [5]:

$$
\begin{gathered}
J_{c}=\frac{\eta U_{i}}{B(W-a)} \\
K_{J c}=\sqrt{\frac{J_{c} E}{\left(1-v^{2}\right)}}
\end{gathered}
$$

where $\mathrm{J}_{\mathrm{c}}$ is the critical $\mathrm{J}$-integral value and $\mathrm{K}_{\mathrm{Jc}}$ is the apparent fracture toughness accounting for the nonlinear load-displacement response. As to the the other terms in eqs. (2) and (3), $U_{i}$ is the energy up to $F_{\max }$, $\eta$ is a geometry factor, $v$ is Poisson's ratio, and $E$ is Young's modulus. The proper time dependent $E$ values were determined with different techniques described elsewhere [6]. 


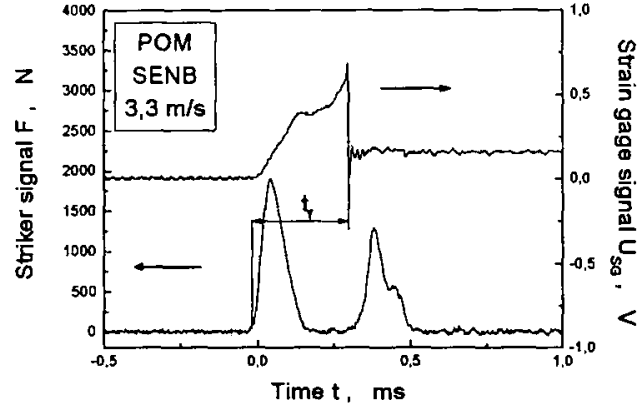

(a)

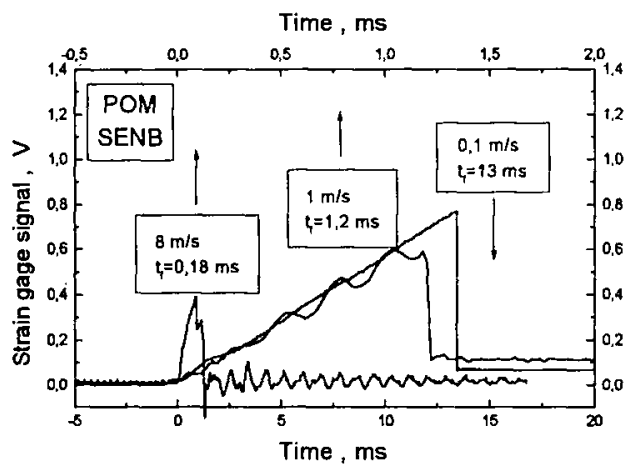

(b)

Fig. 3: Striker force and and strain gage signal (Fig. 3a) and strain gage signals with various testing rates (Fig. 3b) for POM

To characterise the real material response of POM with SENB specimens at impact rates above $1 \mathrm{~m} / \mathrm{s}$, specimens were instrumented with crack tip strain gages (Fig. 3). Fig. 3a shows a typical example of corresponding striker force and the strain gage signals. To determine accurate values for time-to-fracture, $t_{f}$, both signals are required. While the striker signal is more accurate in defining the point of initial load implementation, the strain gage signal reveals a delayed load implementation response. On the other hand, the striker signal reveals no indication of where fracture initiation occurs, a point which can clearly be deduced from the strain gage signal. Based on the crack tip strain gage signal, $\mathrm{K}_{\mathrm{Ic}}$ values may be determined according to various methods $[3,6]$.

Examples of force/load-point displacement curves for the tensile loading mode specimens of the CT and SENT type are shown in Fig. 2 for POM and PE-HD for impact rates of $0.1 \mathrm{~m} / \mathrm{s}, 1 \mathrm{~m} / \mathrm{s}$, and 3.6 to 3.7 $\mathrm{m} / \mathrm{s}$. In contrast to the results with bending specimens (i.e., SENB) in Fig.1, which indicate a limit of about $1 \mathrm{~m} / \mathrm{s}$ for a data reduction scheme based on load-displacement records, the load-displacement results of the tensile load specimens in Fig. 2 apparently are of sufficient quality to determine fracture force values even at loading speeds above $1 \mathrm{~m} / \mathrm{s}$. It is also interesting to note, that the tensile mode SENT specimens of PE-HD reveal a much reduced non-linearity in the load-displacement trace when compared to the corresponding result of SENB specimens (compare Figs. $1 \mathrm{~b}$ and $2 \mathrm{~b}$ ). The improved signal quality of the tensile mode CT and SENT specimens over the bending type SENB specimens is a result of the higher specimen and contact stiffness associated with the former specimen configurations as well as the more effective damping situation in the loading unit

\section{RESULTS AND DISCUSSION}

Experimental results for the effect of the strain rate on $\mathrm{K}_{\mathrm{Ic}}$ and $\mathrm{K}_{\mathrm{Jc}}$ for POM and PE-HD, respectively, are shown in Fig. 4 for various specimen geometries, including also side grooved specimens of PE-HD to enhance the constraint at the crack tip upon loading and to favour the tendency for brittle fracture. The loading rates in these experiments covered the range from 0.001 to $8 \mathrm{~m} / \mathrm{s}$ (approximately four decades). Based on the loading rates, strain rate values for the material surrounding the crack tip were obtained according to a procedure described in $[4,6]$. In general, for both materials good agreement is found in the results for various specimen configurations

For POM in Fig. 4a, $\mathrm{K}_{\mathrm{Ic}}$ is seen to continuously decrease with increasing strain rate up to about $10 \mathrm{~s}^{-1}$. Above this strain rate, the results with CT specimens and instrumented SENB specimens indicate a knee in the $\mathrm{K}_{\mathrm{Ic}}$-strain rate dependence with a stronger drop-off in fracture toughness. The comparison with the results of non-instrumented SENB specimens indicates that this technique is limited to strain rates up to about $10 \mathrm{~s}^{-1}$ (corresponds to impact rates of up to about $1 \mathrm{~m} / \mathrm{s}$ ). Using these $\mathrm{K}_{\mathrm{rc}}$ results together with 
strain rate dependent yield stress values of the POM material investigated, it could be shown that the plain strain fracture toughness concept is applicable [6].

Compared to the results on POM, the apparent fracture toughness $\mathrm{K}_{\mathrm{Jc}}$ of PE-HD (see Fig. 4b) reveals a much more pronounced strain rate dependence in the range from 0.02 up to $5 \mathrm{~s}^{-1}$, with values dropping from about $17 \mathrm{MPam}^{1 / 2}$ to $6 \mathrm{MPam}^{1 / 2}$. At $5 \mathrm{~s}^{-1}$ apparently a minimum in the $\mathrm{K}_{\mathrm{sc}}$-strain rate dependence occurs, an explanation of which needs further investigations.

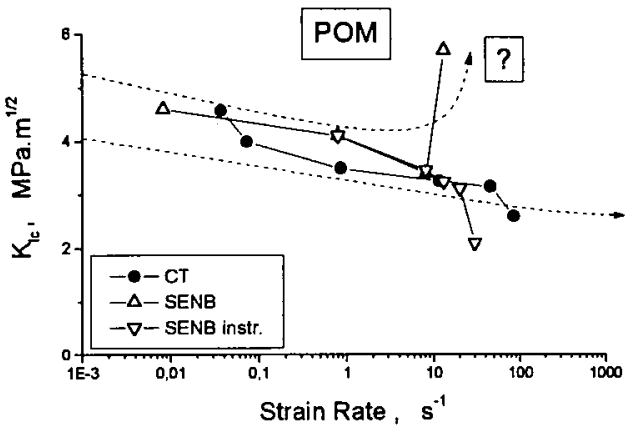

(a)

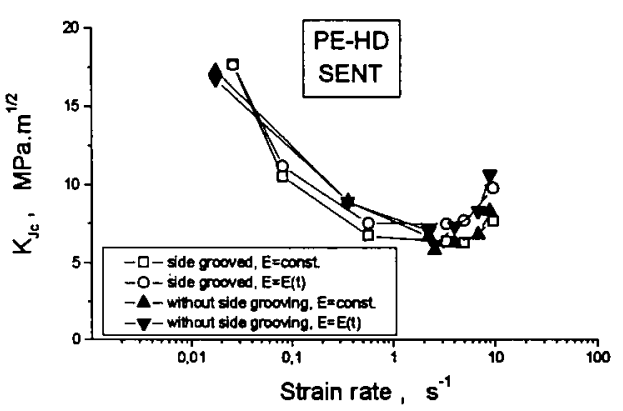

(b)

Fig. 4: Effect of strain rate on $\mathrm{K}_{\mathrm{lc}}$ and $\mathrm{K}_{\mathrm{Jc}}$ for $\mathrm{POM}$ and $\mathrm{PE}-\mathrm{HD}$, respectively, using various specimen geometries

\section{SUMMARY AND CONCLUSIONS}

To characterize the dynamic fracture behaviour of POM and PE-HD, instrumented impact tests were performed in the testing rate range from 0.001 to $8 \mathrm{~m} / \mathrm{s}$ with a servohydraulic test system using various fracture mechanical specimens and data reduction methods. In general, good agreement was found in the results obtained by different methods for each of the materials, revealing a reduction in the characteristic fracture toughness values, $\mathrm{K}_{\mathrm{Ic}}$ and $\mathrm{K}_{\mathrm{Jc}}$ for POM and PE-HD, respectively, with increasing impact rate at least up to about $5 \mathrm{~m} / \mathrm{s}$. In agreement with previous considerations [7], this fracture toughness decrease is thought to be a result of the viscoelastic nature of these materials revealing an increase in yield stress with increasing strain rate and the corresponding reduction in crack tip plastic zone size.

\section{References}

[1] ESIS TC4, A linear elastic fracture mechanics standard for determining $K_{c}$ and $G_{c}$ for plastics, Appendix 3, Draft 7 March 1996

[2] J.G. Williams, M.J. Cawood, Polymer Testing 9 (1990) p. 15-26.

[3] W. Böhme, Application of the Method of Dynamic Key Curves to the determination of Impact fracture Toughness $K_{\text {Id }}$ for ESIS TC4, Draft 1 February 1992

[4] Ph. Beguelin, Phd Thesis, EPFL Lousanne, 1996

[5] T. L. Anderson, Fracture Mechanics, CRC Press, Boca Raton, 1991

[6] Z. Major, Dissertation, Montanuniversität Leoben, in preparation

[7] R. W. Lang et al Fatique Crack Propagation in Short-Glass-Reinforced Nylon 66: Effect of Frequency, in The Role of the Polymer Matrix.., Ed. J. C. Seferis, Plenum Publishing Corp., 1983 